\title{
PERFORMANCE ANALYSIS BY BEMA OF ELECTRICITY AND MAGNETISM COURSES IN ENGINEERING DEGREES USING FLIP TEACHING METHODOLOGIES
}

\author{
S. Bernal-Perez ${ }^{1}$, R. Sabater I Serra ${ }^{1}$, J. Riera², M.A. Gámiz-González², \\ J.A. Gómez-Tejedor' ${ }^{2}$, T. Garcia-Sanchez ${ }^{1}$, J.M. Meseguer-Dueñas ${ }^{2}$, J. Molina- \\ Mateo $^{2}$, M.A. Serrano ${ }^{2}$, I. Tort-Ausina ${ }^{2}$, V. Donderis Quiles ${ }^{1}$, A. Vidaurre ${ }^{2}$ \\ ${ }^{1}$ Departamento de Ingeniería Eléctrica, Universitat Politècnica de València (SPAIN) \\ ${ }^{2}$ Departamento de Física Aplicada, Universitat Politècnica de València (SPAIN)
}

\begin{abstract}
In recent years, new teaching methodologies have entered in the high education scenario: blended learning, problem-based learning, learning-oriented assessment, flip teaching, teamwork and effective oral and written communication are new pedagogical tools used in new instruction strategies.
\end{abstract}

A key issue to guide the application of these new methodologies is the assessment of students performance. One broadly used tool for measure the student's performance in introductory physics is the Brief Electricity and Magnetism Assessment (BEMA), designed specifically as a standardized instrument to evaluate students' qualitative understanding of electricity and magnetism (E\&M) key concepts. The reliability and discriminatory capability of BEMA has been previously studied.

In this paper, BEMA is used to analyse the performance of E\&M students. The E\&M course analyzed is included in two different Bachelor's Degrees: Industrial Electronics and Automation Engineering (DIEA) and Aerospace Engineering (DA) both in Universitat Politècnica de València (UPV), Spain.

They are semester traditional curriculums in which the use of traditional textbooks and screencast have been combined, including flip teaching methodologies. BEMA pre- and post-instruction tests were carried out at the beginning and end of the course respectively.

To deepen understanding of student learning in the E\&M course, correlations of pre- and post-instruction scores have been investigated, identifying the main gain and variance. The relevant information obtained through the BEMA test will allow instructors to monitor the use of new methodologies and teaching tools.

Keywords: assessment, learner-centred teaching, BEMA test, innovation effectiveness.

\section{INTRODUCTION}

In the last decades, facilitated by the Information and Communications Technology, many innovations in higher education environments have been proposed. Among them, blended learning, problem solving strategies, teamwork flip teaching, [1]-[4]. When one innovation is brought to classroom, many factors can influence its success or failure: it has been adequately implemented? Were the instructors/students prepared for the innovation? Was the effectiveness correctly measured?

Then, a key question is, how can the innovation benefits be evaluated? Some possible answers are final marks or students and instructors' opinion. However, although they should be taken into account, it is better if an objective assessment tool is introduced. Several standardized assessments in introductory physics (i.e., concept inventories) have been proposed. Among others, Brief Electricity and Magnetism Assessment (BEMA) was developed in 1997 by Chabay and Sherwood, in collaboration with Fred Reif, [5]. This standardized multiple-choice test has been extensively used to assess students' understanding about electricity and magnetism concepts [6], [7]. The performance of a group of students can be compared with other through the BEMA test results. It enables the comparison of students learning enrolled in different degrees, following different methodologies, and also measures the effect of the application of an innovation. The effect can be analysed as a function of student's course gain (differences between post-test and pre-test) [7]. In a previous work, [8] it was verify that BEMA test offered adequate discrimination and reliability as a tool to measure students' understanding of electricity and magnetism, when applied to students of Electricity courses in engineering degrees at the UPVSpain. 
In this paper, the electricity and magnetism course performance was analysed for two different Bachelor's Degrees: Industrial Electronics and Automation Engineering (DIEA) and Aerospace Engineering (DA) both at the UPV. The BEMA test was provided to students twice, before (pre-test) and after (post-test) completing the electrical and magnetic courses. In a previous paper [9], the gain in the BEMA test was analysed in three categories: electrostatics, dc current and magnetostatics. The highest gain was obtained for magnetostatics, for both degrees. Also, the learning persistence was studied for the DIEA curriculum [10]. The results showed a clear correlation between the student's course grades, the gain and the learning persistence over time. In order to get a more in-deep analysis, in this work, $B E M A$ results are studied as a function of the final course grades.

\section{METHODOLOGY}

The E\&M course analysed is included in the Bachelor's Degree in Industrial Electronics and Automation Engineering (DIEA) and Aerospace Engineering (DAE) at the School of Engineering Design-Universitat Politècnica de València (UPV-Spain). Lessons of the introductory E\&M course at UPV are structured through the term in two 90 minutes lesson per week, and 2 hours laboratory session every other week. The methodology used is a combination of flip-teaching $(\mathrm{FT})$ and traditional methodologies, where the university's e-learning platform was intensively employed. For Aerospace Engineering (DA), the E\&M lessons correspond to the last part of an annual Physics course. The E\&M part is taught for 8 weeks following the same methodology described above. In the case of Industrial Electronics and Automation Engineering (DIEA), the E\&M lessons correspond to a complete course called Electricity that is taught during 15 weeks following the same methodology. The FT methodology used in both courses is based on videos, instructor's notes and self-assessment tests available for students in the UPV online learning platform (PoliformaT, based on Sakai technology).

The data collected in this study contain the results of the students' responses to the BEMA test which was delivered to the same students twice; first at the beginning of the E\&M course and then after its completion (BEMA01 and BEMA02, respectively). BEMA test was given following the standard instructions.

\subsection{Description of gain calculation}

In order to assess the students' performance improvement related to the application of new methodologies, an objective assessment tool is introduced by defining an index, the normalized gain. It was introduced by Hake in 1998 [11] and it is defined to measure students learning degree after an instruction process. This index is defined as the ratio of the individual gain to the maximum possible gain:

$$
\bar{g}=\frac{\overline{S_{f}}-\overline{S_{l}}}{10-\overline{S_{l}}}
$$

Where $\overline{S_{l}}$ and $\overline{S_{f}}$ are the mean grades (out of 10 ) of the pre- and post-test (BEMA01 and BEMA02) for each course.

Numerous papers [12]-[16] use the normalized gain given by eq. (1) as a measure of students learning in several disciplines relates to science and engineering. The normalized gain of Hake allows categorizing the data obtained in three zones in the following way: low, if it is less than 0.3; medium, if it is between 0.3-0.7 and high if it is greater than 0.7.

\subsection{Data Analysis}

Data has been analysed on SPSS software on Windows Version 16 (IBM, Somers, NY, USA). The input data for the analysis were the students gains calculated as a percentage, applying eq. (1),

Descriptive table, in the SPSS shows statistics that are more useful. To simplify the analysis, in this paper, only significant parameters are presented: Number of students in different groups, mean, standard deviation for separate groups, as well as all groups combined, and standard error.

The results obtained from a preliminary analysis identify an aspect that could interfere the results, the outliers. De-motivated students that made the test in a random manner. Fortunately, their marks are far away from the mean and easy to identify and discard. 
Table 1 Total data Descriptive table

\begin{tabular}{l|c|c|c|c}
\hline \hline & Number of students & Mean gain & Std. Deviation & Std. Error \\
\hline AE & 36 & 13,99 & 19,41 & 3,23 \\
\hline Elec_01 & 12 & 27,17 & 24,66 & 7,12 \\
\hline Elec_02 & 57 & 16,22 & 21,79 & 2,88 \\
\hline Elec_03 & 39 & 8,21 & 23,04 & 3,69 \\
\hline Total & 144 & 14,41 & 22,17 & 1,84 \\
\hline \hline
\end{tabular}

Table 1 shows the summary of the input data analysed. A total of 144 students' performance were analysed, without outliers.

Students of DAE are organized in only one group (AE), formed by 36 students.

The rest of the students, 108, are DIEA students, in three different classes (Elec_01, Elec_02 and Elec_03), with different schedule and different instructors.

The mean gain calculated shows better gain in the Elec 01 group due that this group is included in a government education program (ARA program). ARA- Alto Rendimiento Académico stands for "High Academic Performance" and only student with high grades can enrol in this specific program. Student is this group have obtained high grades from the University Admission Test (more than 12 points over 14). DIEA groups have been consider as a whole, to prevent this segmentation from influencing the study outcomes.

\section{RESULTS}

The aim of the present study is to find out possible influences in the students' performance. ANOVA test is going to be used to identify the significant different among hypothetic levels.

Note that the ANOVA alone does not tell specifically which mean values are different from each other, therefore, further analysis is required. In our case, orthogonal contrast was used for further analysis.

Using SPSS tool, Table 2 shows the output of the ANOVA analysis. The most important value of this table is the Significance. It shows whether there is a statistically significant difference between levels (confidence level 95\%, $p \leq 0.05$ ).

\subsection{Influence of degree and final grade}

The first hypothesis to be verified is the influence of degree and final grade in the BEMA results.

The first variable, degree, has two possible values, DAE and DIEA, considering all the DIEA classes as a whole.

Grade is the final grade obtained at the end of the E\&M course. This final grade will be used to perform an in-depth analysis, grouping the students in terciles from highest to lowers grades: lower, middle and upper tercile.

To assess the impact of these variables, a two-way ANOVA test is performed. The variables considered have been both degree and grade defined above. The results are shown in Table 2.

Table 2 Two way ANOVA test results

\begin{tabular}{l|c|c|c|c|c}
\hline \hline \multicolumn{1}{c|}{ Source } & $\begin{array}{c}\text { Sum of } \\
\text { Squares }\end{array}$ & $\begin{array}{c}\text { Degrees of } \\
\text { freedom }\end{array}$ & Mean Square & F-statistic & $\begin{array}{c}\text { Significance } \\
(\boldsymbol{p})\end{array}$ \\
\hline Degree & 1.18 & 1 & 1.18 & 0.003 & 0.96 \\
\hline Grade & 4963.14 & 2 & 2481.57 & 5.52 & 0.005 \\
\hline Degree * Grade & 252.59 & 2 & 126.30 & 0.28 & 0.76 \\
\hline \hline
\end{tabular}

The variables have been studied separately and combined. 
The analysis of variance depicted in Table 2 stands out that there are not significant differences between degrees and only the final grade is significant $(0.005<0.05)$. It can also be pointed out that the interaction between the two variables, degree and grade, is not relevant either.

\subsection{Effect of levels}

From data on Table 1, the levels defined by classroom are not valid because they are influenced by instructors, schedules, etc. A new classification has been performed based on grade results to avoid this problem. In addition, degree has become non-significant, from to results in Table 2.

As state before (section 3.1), the students have been divided in three levels, regarding the grades obtained at the end of the E\&M course (upper (L1), middle (L2) and lower (L3) tercile).

To confirm the results of previous study, AE and DIEA are considered separately.

\subsubsection{Aerospace Engineering. (DA)}

AE class (Table 1), with 36 students, has been classified in three terciles regarding the final mark: AEL1 lower, AEL2 middle and AEL3 upper tercile. The mean gain, obtained applying equation (1), has been calculated using SPSS tool. Table 3 shows the data obtained from this analysis and the mean gain as function of the terciles has been represented in Figure 1.

Table 3 Aerospace Engineering Degree (AE) Descriptive table

\begin{tabular}{l|c|c|c|c}
\hline \hline \multicolumn{1}{c|}{ Level } & Number of students & Mean gain & Std. Deviation & Std. Error \\
\hline AEL1 & 13 & 7,98 & 19,32 & 5,36 \\
\hline AEL2 & 11 & 13,21 & 21,92 & 6,60 \\
\hline AEL3 & 12 & 21,23 & 15,95 & 4,60 \\
\hline Total & 36 & 13,99 & 19,41 & 3,24 \\
\hline \hline
\end{tabular}

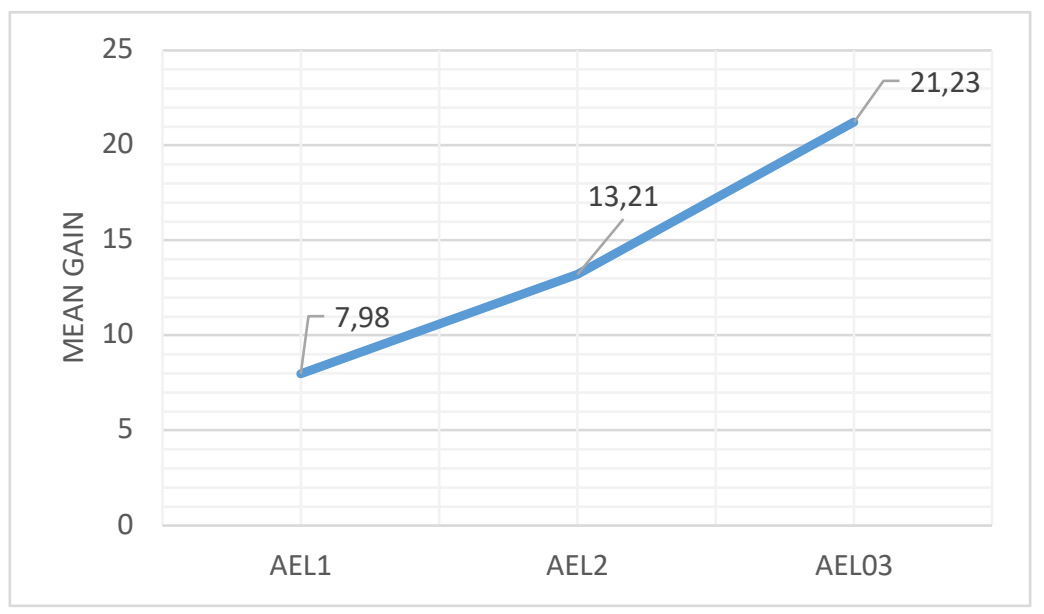

Figure 1. Mean gains in three Aerospace Engineering levels

The comparison of results from all DAE students indicates that, as expected, most the students obtain a higher score after the end of the course. The increase in the rating, the gain, is higher in the upper tercile (AEL03). These students, with the same didactic methodology as the rest of students, obtain a higher academic performance.

In order to analyse if the different performance is due to belong to a specific tercile, one way ANOVA test was performed and results showed in Table 4. 
Table 4 One Way ANOVA test in Aerospace Engineering Degree (AE)

\begin{tabular}{l|c|c|c|c|c}
\hline \hline \multicolumn{1}{c|}{ Source } & $\begin{array}{c}\text { Sum of } \\
\text { Squares }\end{array}$ & $\begin{array}{c}\text { Degrees of } \\
\text { freedom }\end{array}$ & Mean Square & F-statistic & Significance \\
\hline Between Groups & 1105,67 & 2 & 552,84 & 1,51 & 0,24 \\
\hline Within Groups & 12080,98 & 33 & 366,09 & & \\
\hline Total & 13186,65 & 35 & & & \\
\hline \hline
\end{tabular}

Although the mean gain in Table 3 shows an increasing order (AEL1<AEL02, AEL03), ANOVA analysis (Table 4$)$ does not show significant differences $(0.24>0.05)$.

\subsubsection{Industrial Electronics and Automation Engineering (DIEA)}

The same terciles classification has been applied to the DIEA students. Each class has been divided in three terciles and 9 subgroups were finally analysed (ELEC_01_L1 to ELEC_01_L3, ELEC_02_L1 to ELEC_02_L3 and ELEC_03_L1 to ELEC_03_L3). Corresponding levels are grouped into three terciles: ELECL̄1, ELLEL2 and ELEECL3.

Within the new classification defined, the mean gain has been calculated and results showed in Table 5.

Table 5 Industrial Electronics and Automation Engineering (DIEA) Descriptive table

\begin{tabular}{l|c|c|c|c}
\hline \hline \multicolumn{1}{c|}{ Level } & Number of students & Mean gain & Std. Deviation & Std. Error \\
\hline ELECL1 & 34 & 7,0896 & 21,71611 & 3,72428 \\
\hline ELECL2 & 37 & 10,3196 & 20,81333 & 3,42169 \\
\hline ELECL3 & 37 & 25,6378 & 22,88846 & 3,76284 \\
\hline Total & 108 & 14,5507 & 23,10489 & 2,22327 \\
\hline
\end{tabular}

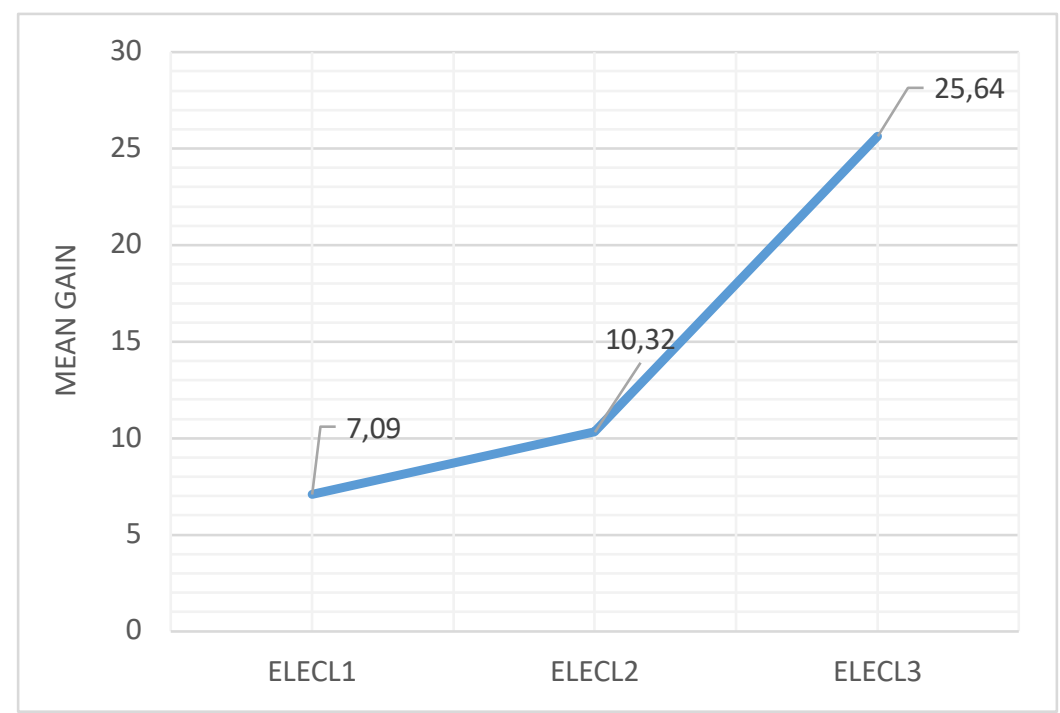

Figure 2 Mean gains for three terciles defined in Electronics and Automation Engineering Degree (DIEA)

As for Aerospace Engineering groups, there is an increasing order in the mean gain: ELECL1<ELECL2<ELECL3. The analysis of variance from the influence of the tercile in the gain was analysed and the results are shown in Table 6. 
Table 6 One Way ANOVA Test in Industrial Electronics and Automation Engineering Degree (DIEA)

\begin{tabular}{l|c|c|c|c|c}
\hline \hline \multicolumn{1}{c|}{ Source } & Sum of Squares & Degrees of freedom & Mean Square & F-statistic & Significance \\
\hline Between Groups & 7103.26 & 2 & 3551.63 & 7.46 & 0.001 \\
\hline Within Groups & 50017.19 & 105 & 476.35 & & \\
\hline Total & 57120.46 & 107 & & & \\
\hline \hline
\end{tabular}

In order to perform a deeper analysis into these differences, orthogonal contrast was performed. The results indicated that ELECL3>(ELECL2,ELECL1).

Figure 3 represents results from Table 3 and Table 5, comparing the results of the two degrees analysed in this study.

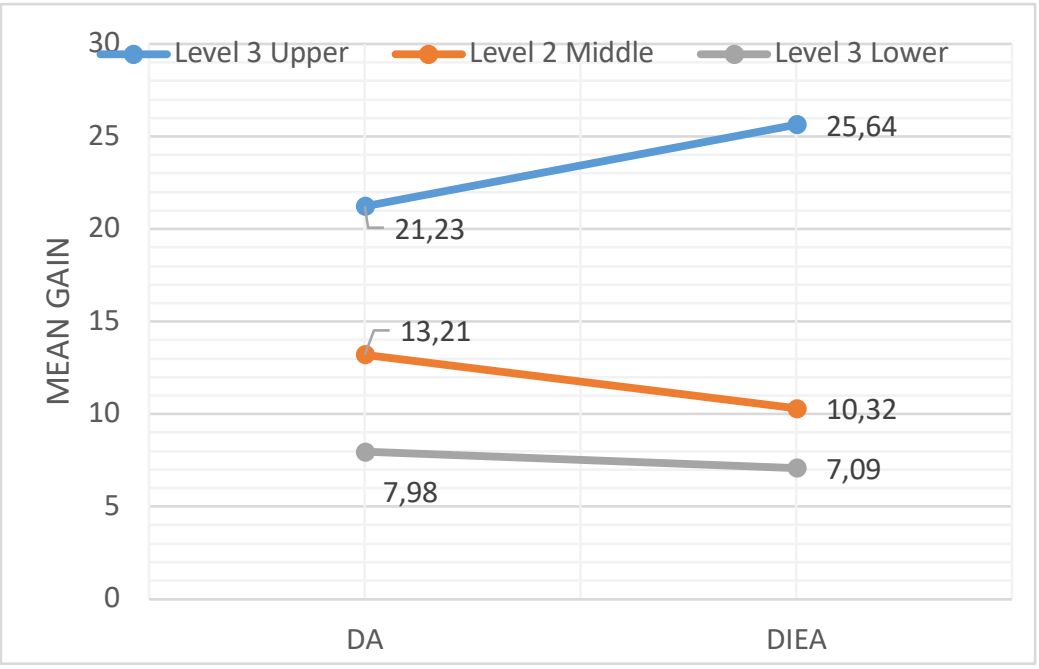

Figure 3 Mean gains for three terciles in both degrees (DAE and DIEA)

\section{CONCLUSIONS}

In this paper, performance of students of E\&M courses have been analysed through the Brief electricity and magnetism assessment (BEMA). The population of students comprise different degrees, classes and instructors. With this wide heterogeneity in the population, it was necessary to study the significance of these differences, in order to adapt new teaching methodologies to improve learning. Different studies have been carried out focused on determining the main significant variables.

The results indicate that (after applying ANOVA tests) the specific degree is not the relevant aspect in the results obtained from BEMA test. We found that the level (tercile) which the students are positioned (upper, middle or lower) is the determinant factor. Students from the upper tercile show the best results with a wide difference with the rest of them. Students who start the course with a solid knowledge base demonstrate more capacity and ability to learn through the course.

On the contrary, particular attention must be paid to students positioned in the middle and lower tercile in order to improve their learning during the course. These students, who start the course with low knowledge base, despite increasing their knowledge along the course, obtain lower grades because a superficial, non-deep learning.

It has been stated a clear relationship between the type of students and the evolution of learning. This study will allow us to adapt the didactic methods and reinforce the activities proposed accordingly, focusing particularly on students belonging to middle and lower tercile, with a view to increase their learning performance. 


\section{ACKNOWLEDGEMENTS}

This work has been supported by the Universitat Politècnica de València through the Project of Innovation and Educational Improvement Program (Projects PIME/2018/B26 and PIME/2018/B25 Convocatoria de Proyectos de Innovación y Convergencia).

\section{REFERENCES}

[1] W.-L. Shih and C.-Y. Tsai, "Students' perception of a flipped classroom approach to facilitating online project-based learning in marketing research courses," Australas. J. Educ. Technol., Dec. 2016.

[2] Q. Liu, W. Peng, F. Zhang, R. Hu, Y. Li, and W. Yan, "The effectiveness of blended learning in health professions: systematic review and meta-analysis," J. Med. Internet Res., vol. 18, no. 1, p. e2, Jan. 2016.

[3] M. J. Stadler, N. Becker, S. Greiff, and F. M. Spinath, "The complex route to success: complex problem-solving skills in the prediction of university success," High. Educ. Res. Dev., vol. 35, no. 2, pp. 365-379, Mar. 2016.

[4] C. Adachi, J. H.-M. Tai, and P. Dawson, "Academics' perceptions of the benefits and challenges of self and peer assessment in higher education," Assess. Eval. High. Educ., vol. 43, no. 2, pp. 294306, Feb. 2018.

[5] R. Chabay and B. Sherwood, "Restructuring the introductory electricity and magnetism course," $\mathrm{Am}$. J. Phys., vol. 74, no. 4, pp. 329-336, 2006.

[6] M. W. McColgan, R. A. Finn, D. L. Broder, and G. E. Hassel, "Assessing students' conceptual knowledge of electricity and magnetism," Phys. Rev. Phys. Educ. Res., vol. 13, no. 2, p. 020121, 2017.

[7] M. A. Kohlmyer et al., "Tale of two curricula: The performance of 2000 students in introductory electromagnetism," Phys. Rev. Spec. Top. - Phys. Educ. Res., vol. 5, no. 2, p. 020105, 2009.

[8] M. A. Gamiz-Gonzalez et al., "Evaluating reliability and discriminatory capability of bema in two Spanish engineering degrees," in Education and new Developments, 2019, vol. II, pp. 303-305.

[9] A. Vidaurre et al., "Measuring Innovation Effectiviness by Means of a Conceptual Test of Electricity and Magnetism," in INTED2019 Proceedings, 2019, pp. 8728-8733.

[10] T. García-Sánchez et al., "Assessing outcomes in electricity and magnetism courses in engineering degrees. Students' performance analysed by BEMA," in Education and new Developments, 2019, vol. II, pp. 144-148.

[11] R. R. Hake, "Interactive-engagement versus traditional methods: A six-thousand-student survey of mechanics test data for introductory physics courses," Am. J. Phys., vol. 66, no. 1, pp. 64-74, Jan. 1998.

[12] L. Bao, "Theoretical comparisons of average normalized gain calculations," Am. J. Phys., vol. 74, no. 10, pp. 917-922, Oct. 2006.

[13] V. P. Coletta and J. A. Phillips, "Interpreting FCl scores: Normalized gain, preinstruction scores, and scientific reasoning ability," Am. J. Phys., vol. 73, no. 12, pp. 1172-1182, Dec. 2005.

[14] J. M. Nissen, R. M. Talbot, A. Nasim Thompson, and B. Van Dusen, "Comparison of normalized gain and Cohen's d for analyzing gains on concept inventories," Phys. Rev. Phys. Educ. Res., vol. 14, no. 1, p. 010115, Mar. 2018.

[15] J. D. Marx and K. Cummings, "Normalized change," Am. J. Phys., vol. 75, no. 1, pp. 87-91, Jan. 2007.

[16] S. D. Willoughby and A. Metz, "Exploring gender differences with different gain calculations in astronomy and biology," Am. J. Phys., vol. 77, no. 7, pp. 651-657, Jul. 2009. 